\title{
Lipoprotein Lipase Regulates Fc Receptor-mediated Phagocytosis by Macrophages Maintained in Glucose-deficient Medium
}

\author{
Baoyun Yin, ${ }^{\star}$ John D. Loike, ${ }^{\ddagger}$ Yuko Kako, ${ }^{\star}$ Peter H. Weinstock, ${ }^{\S}$ Jan L. Breslow, ${ }^{\S}$ Samuel C. Silverstein, ${ }^{\ddagger}$ and Ira J. Goldberg ${ }^{\star}$ \\ $*$ Department of Medicine and ${ }^{\ddagger}$ Department of Physiology and Biophysics, Columbia University College of Physicians and Surgeons, \\ New York 10032; and ${ }^{\S}$ Laboratory of Biochemical Genetics and Metabolism, The Rockefeller University, New York 10021
}

\begin{abstract}
During periods of intense activity such as phagocytosis, macrophages are thought to derive most of their energy from glucose metabolism under both aerobic and anaerobic conditions. To determine whether fatty acids released from lipoproteins by macrophage lipoprotein lipase (LPL) could substitute for glucose as a source of energy for phagocytosis, we cultured peritoneal macrophages from normal and LPL knockout (LPL-KO) mice that had been rescued from neonatal demise by expression of human LPL via the muscle creatine kinase promoter. Normal and LPL-KO macrophages were cultured in medium containing normal (5 mM) or low (1 mM) glucose, and were tested for their capacity to phagocytose IgG-opsonized sheep erythrocytes. LPL-KO macrophages maintained in 1 and $5 \mathrm{mM}$ glucose phagocytosed 67 and $79 \%$ fewer IgG-opsonized erythrocytes, respectively, than macrophages from normal mice. Addition of VLDL to LPL-expressing macrophages maintained in $1 \mathrm{mM}$ glucose enhanced the macrophages' phagocytosis of IgGopsonized erythrocytes, but did not stimulate phagocytosis by LPL-KO macrophages. Inhibition of secreted LPL with a monoclonal anti-LPL antibody or with tetrahydrolipstatin blocked the ability of VLDL to enhance phagocytosis by LPL-expressing macrophages maintained in $1 \mathrm{mM}$ glucose. Addition of oleic acid significantly enhanced phagocytosis by both LPL-expressing and LPL-KO macrophages maintained in $1 \mathrm{mM}$ glucose. Moreover, oleic acid stimulated phagocytosis in cells cultured in non-glucose-containing medium, and increased the intracellular stores of creatine phosphate. Inhibition of oxidative phosphorylation, but not of glycolysis, blocked the capacity of oleic acid to stimulate phagocytosis. Receptor-mediated endocytosis of acetyl LDL by macrophages from LPL-expressing and LPL-KO mice was similar whether the cells were maintained in 5 or 1 $\mathrm{mM}$ glucose, and was not augmented by VLDL. We postulate that fatty acids derived from macrophage LPL-catalyzed hydrolysis of triglycerides and phospholipids provide energy for macrophages in areas that have limited amounts
\end{abstract}

Baoyun Yin and John D. Loike contributed equally to this study.

Address correspondence to Ira J. Goldberg, M.D., Department of Medicine, Columbia University, 630 West 168th Street, New York, NY 10032. Phone: 212-305-3678; FAX: 212-305-5384; E-mail: IJG3@ columbia.edu

Received for publication 4 November 1996 and accepted in revised form 24 April 1997.

J. Clin. Invest.

(c) The American Society for Clinical Investigation, Inc. 0021-9738/97/08/0649/09 \$2.00

Volume 100, Number 3, August 1997, 649-657

http://www.jci.org of ambient glucose, and during periods of intense metabolic activity. (J. Clin. Invest. 1997. 100:649-657.) Key words: lipoproteins $\bullet$ fatty acids $\bullet$ glucose $\bullet$ abscess $\bullet$ atherosclerosis

\section{Introduction}

Macrophages are long-lived motile phagocytes that play vital roles in host defense against microorganisms, in removal of senescent cells and matrix proteins, and in resorption of damaged and necrotic tissues. Macrophages survive and function under the metabolically unfavorable circumstances of ischemic and avascular (e.g., abscesses) tissues, a trait which distinguishes them from fibroblasts, epithelial, and muscle cells. The capacity of macrophages to function under adverse conditions may be due in part to their ability to use many different substrates to generate metabolic energy. While glucose is their favored fuel under most conditions, macrophages at rest in vitro have been shown to generate ATP from glutamine, lactate, and keto-acids to varying degrees (1-3), depending on their state of differentiation (e.g., peritoneal vs. alveolar macrophages) $(4,5)$.

Fatty acids are another source of fuel $(4,6)$, but are the least readily available of the circulating energy sources. Most of the fatty acids in blood or other extracellular fluids are contained within lipoproteins where they are linked covalently to glycerol, and form triglycerides and phospholipids. There are two ways in which macrophages could obtain fatty acids from lipoproteins. One is to endocytose the lipoproteins. Endocytosed lipoproteins are delivered to lysosomes where their proteins and glycerides are hydrolyzed, thereby releasing fatty acids and other degradation products into the cytoplasm where they are available for further metabolism. Macrophages, however, endocytose few large, triglyceride-rich lipoproteins unless they have been partially metabolized $(7,8)$. The second pathway involves extracellular hydrolysis of glycerides in lipoproteins, which allows the uptake primarily of the released free fatty acids (9), and is the major pathway responsible for fatty acid assimilation by adipocytes and myocytes (10). This pathway requires the actions of cell surface lipoprotein lipase (LPL). ${ }^{1}$

Macrophages, unlike other phagocytic leukocytes (e.g., neutrophils, eosinophils, basophils), have evolved a method to obtain fatty acids without ingestion of whole lipoproteins. Macrophages secrete LPL $(8,9)$, the major enzyme responsible for extracellular release of fatty acids from triglyceride-rich

1. Abbreviations used in this paper: 2-DG, 2-deoxy-D-glucose; $\mathrm{CrP}$, creatine phosphate; DFBS, dialyzed fetal bovine serum; DiI-AcLDL, $11^{\prime}$-dioctadecyl-3,3,3',3'-tetramethylindidocarbocyanine perchlorate acetyl LDL; E(IgG), IgG-opsonized sheep erythrocytes; ${ }^{125}$ I-ox LDL, ${ }^{125}$ I-labeled oxidized LDL; KO, knockout; L0-MCK, LPL knockout mice whose macrophages make no LPL; LPL, lipoprotein lipase; MCK, muscle creatine kinase; RBC, red blood cells; RT, reverse transcription; THL, tetrahydrolipstatin. 
lipoproteins. LPL activity is increased when macrophages are activated $(11,12)$, a time when energy requirements are also increased. A role for this enzyme in macrophage physiology other than lipoprotein and lipid uptake has been suggested (for review see reference 13), but has not been tested. The availability of mice with macrophages genetically incapable of expressing LPL and of specific LPL inhibitors allowed us to test whether fatty acids derived from LPL-mediated hydrolysis of exogenously supplied lipoproteins fuel phagocytosis, an energy-dependent process generally thought to be fueled primarily by glucose. Our studies show that they do, but only under conditions where glucose is limiting.

\section{Methods}

Animals. Levak-Frank et al. (14) produced a transgenic mouse in which human LPL, encoded by an LPL minigene driven by a muscle creatine kinase (MCK) promoter, was expressed only in skeletal muscle. LPL knockout (KO) mice (15) were crossed with these LPL transgenic animals yielding mice whose macrophages make no LPL. We term these L0-MCK mice, and their macrophages LPL-KO. Elicited peritoneal macrophages were obtained from 4-6 mo-old L0MCK mice and normal mice of similar age and strain (primarily C57BL/6)

Preparation of macrophages. Macrophages from both normal and L0-MCK mice were obtained and cultured as described $(16,17)$. In brief, macrophages were harvested by peritoneal lavage $4 \mathrm{~d}$ after injection of $1.0 \mathrm{ml}$ thioglycollate broth. Cells were washed with PBS containing $1.0 \mathrm{mM} \mathrm{Ca}$ and $0.5 \mathrm{mM} \mathrm{Mg}$ and were plated in DMEM containing 10\% FBS (Life Technologies Inc., Grand Island, NY) or FBS dialyzed against PBS (DFBS) (Life Technologies Inc.). Nonadherent cells were removed by washing with DMEM $2 \mathrm{~h}$ after plating. Macrophages were maintained in DMEM $+10 \%$ FBS. After 3-4 d in culture, the cells were switched to DMEM containing the indicated amounts of glucose and lipoproteins before assays.

Cell culture media. Normal glucose medium consisted of DMEM (5 mM glucose) $+10 \%$ FBS or DFBS. Low glucose medium consisted of DMEM (1 mM glucose) + 10\% DFBS (16) with or without human VLDL $(100 \mu \mathrm{g} / \mathrm{ml})$. No glucose media consisted of $0 \mathrm{mM}$ glucose +10 DFBS. In some experiments, macrophages were incubated in medium containing $0.4 \mathrm{mM}$ oleic acid (18) (Sigma Chemical Co., St. Louis, MO) in DMEM containing 10\% DFBS and $2 \%$ fatty acid-free BSA (Sigma Chemical Co.) or control media also containing added BSA.

THP-1 cells, a human macrophage-like cell line, were incubated in $95 \%$ air $/ 5 \% \mathrm{CO}_{2}$ for $48 \mathrm{~h}$ at $37^{\circ} \mathrm{C}$ in RPMI (Life Technologies, Inc.) containing $10 \% \mathrm{FBS}$ and $1.6 \times 10^{-7} \mathrm{M}$ phorbol myristate acetate (Sigma Chemical Co.) to induce LPL synthesis and secretion (19). The cells then were incubated in fresh medium as follows: normal RPMI (10 mM glucose + 10\% FBS), low glucose RPMI (1 mM glucose $+10 \%$ DFBS $)$, with or without human VLDL $(100 \mu \mathrm{g} / \mathrm{ml})$.

Measurement of LPL. Macrophages were plated and incubated in DMEM $+10 \%$ FBS for $3 \mathrm{~d}$. The medium was collected and assayed immediately for LPL activity. LPL was assayed by a modification of a method described previously (20). Chicken antibovine milk LPL antiserum (made as described by Goers et al. [21] and which cross-reacts with murine LPL) and mouse anti-human LPL monoclonal $\operatorname{IgG}(22)$ were used to confirm the identity of the lipase measured.

LPL RNA. Total cellular RNA was extracted from the same macrophages used for LPL measurements (Trisolv solution; Biotecx Laboratories, Houston, TX), according to the manufacturer's instructions. In brief, $2 \times 10^{6}$ cells in a $35-\mathrm{mm}$ dish were lysed in $1 \mathrm{ml}$ icecold Trisolv. The Trisolv solution was extracted with $0.2 \mathrm{ml}$ of chloroform, the aqueous phase was separated, and $0.5 \mathrm{ml}$ of isopropanol was added to precipitate the RNA. RNA was suspended in $\mathrm{H}_{2} \mathrm{O}$. Re- verse transcription (RT)-PCR on total RNA was performed with the following primers: 5'-CCTCAAGGGAAAGCTGCCCAC-3' and 5'-GTTACCGTCCAGCCATGGATCACCA-3' for human LPL. The 5' primer was from the untranslated region of human LPL's first exon and the $3^{\prime}$ primer spanned the junction of human LPL's next two exons. 5'-CTCGTCGGCACCGTTGAGCCTCGTTACCG-3' and 5'-ACTGGAGCGCGGTGGAGCGCCGTAGGGCA-3' for mouse LPL. RNA was reverse transcribed into cDNA (Gene Amp RNA PCR kit; Perkin-Elmer Corp., Norwalk, CT). In brief, the reverse transcription mixture containing $1 \mu \mathrm{g}$ total RNA from peritoneal macrophages, and random hexamer primer were incubated at room temperature for $10 \mathrm{~min}, 42^{\circ} \mathrm{C}$ for $15 \mathrm{~min}$, heated to $99^{\circ} \mathrm{C}$ for 5 min, and then cooled to $5^{\circ} \mathrm{C}$ for $5 \mathrm{~min}$. After reverse transcription, 40 $\mu l$ of the cDNA mixture was amplified with the primers indicated using standard protocols $(14,15)$. For human LPL, the protocol involved 30 cycles of $93^{\circ} \mathrm{C}$ for $1 \mathrm{~min}, 65^{\circ} \mathrm{C}$ for $1 \mathrm{~min}$, and $72^{\circ} \mathrm{C}$ for $2 \mathrm{~min}$. For mouse LPL, PCR amplification was done using 45 cycles at $93^{\circ} \mathrm{C}$ for $1 \mathrm{~min}$ and $72^{\circ} \mathrm{C}$ for $3 \mathrm{~min}$. Reaction products were resolved by gel electrophoresis, and were visualized by ethidium bromide staining.

Phagocytosis. Cells were maintained under the culture conditions indicated in Results for $48 \mathrm{~h}$ before phagocytosis assays, were washed with PBS, and were incubated for $1 \mathrm{~h}$ in $500 \mu \mathrm{l} \mathrm{PBS}$ containing the indicated glucose concentration and $40 \mu \mathrm{l}$ of a $1 \% \mathrm{vol} / \mathrm{vol}$ suspension of IgG-opsonized sheep erythrocytes $(\mathrm{E}[\mathrm{IgG}])$. Uningested red blood cells $(\mathrm{RBC})$ were lysed by washing sequentially with $\mathrm{PBS}, \mathrm{H}_{2} \mathrm{O}$, and PBS. The cells were then fixed in $2.5 \%$ glutaraldehyde, and the number of ingested RBCs per 100 macrophages was assayed using a phase-contrast microscope. Phagocytosis index is the number of RBC ingested per 100 cells $(16,17)$.

To measure receptor-mediated endocytosis of $11^{\prime}$-dioctadecyl$3,3,3^{\prime}, 3^{\prime}$-tetramethylindidocarbocyanine perchlorate acetyl LDL (DiIAcLDL), $2 \times 10^{6}$ macrophages were cultured in each well of 12-well plates for $48 \mathrm{~h}$ in the medium indicated. Cells then were washed in serumless DMEM containing $1 \mathrm{mM}$ glucose and $0.3 \%$ BSA, incubated at $37^{\circ} \mathrm{C}$ for $2 \mathrm{~h}$ in $500 \mu \mathrm{l}$ of the same medium containing $3.5 \mu \mathrm{g}$ DiIAcLDL. To remove the noninternalized AcLDL, the cells were washed three times with the same medium, incubated at $37^{\circ} \mathrm{C}$ for 15 min in DMEM containing $1 \mathrm{mM}$ glucose, $0.3 \% \mathrm{BSA}$, and $100 \mathrm{U} / \mathrm{ml}$ of heparin, and washed with PBS at room temperature. The cells were then incubated with $200 \mu \mathrm{l}$ methanol to extract DiI from internalized DiI-AcLDL. DiI in the cell extract was quantitated using a fluorescence plate reader (El Khoury, Silverstein and Loike, manuscript in preparation).

For receptor-mediated endocytosis of ${ }^{125}$ I-labeled oxidized LDL ( ${ }^{125} \mathrm{I}$-oxLDL) (prepared as described by Sparrow et al. [23]) $0.5 \times 10^{6}$ macrophages were maintained for $48 \mathrm{~h}$ in each well of 24-well plates in the same medium used for uptake of DiI-AcLDL. The cells then were washed with DMEM containing $1 \mathrm{mM}$ glucose and $0.3 \%$ BSA, and were incubated at $37^{\circ} \mathrm{C}$ for $1 \mathrm{~h}$ in $500 \mu \mathrm{l}$ of the same medium containing $7 \mu \mathrm{g}\left(2.1 \times 10^{6} \mathrm{cpm}\right){ }^{125} \mathrm{I}$-oxLDL. To remove cell surfaceassociated ${ }^{125}$ I-oxLDL, the cells were washed three times with DMEM, $1 \mathrm{mM}$ glucose, $0.3 \%$ BSA, and were incubated for $15 \mathrm{~min}$ in the same medium with $100 \mathrm{U} / \mathrm{ml}$ heparin. The cells were washed with PBS, and were then lysed with $500 \mu \mathrm{l}$ of $0.1 \mathrm{~N} \mathrm{NaOH}$. Aliquots of the cell lysates were counted with an autogamma spectrometer.

Metabolic studies. To assess cellular glucose uptake and retention during phagocytosis and receptor-mediated endocytosis, we used 2-deoxy-D-glucose (2-DG; DuPont NEN, Boston, MA), a glucose analog that is converted to 2-deoxyglucose 6 phosphate but not metabolized further $(17,24)$. Macrophages cultured for $48 \mathrm{~h}$ on coverslips in $1 \mathrm{mM}$ glucose DMEM $+10 \%$ FBS were washed in PBS, and were then incubated for $60 \mathrm{~min}$ in $500 \mu \mathrm{l}$ of DMEM, $1 \mathrm{mM}$ glucose, $0.3 \%$ BSA, and $3 \mu \mathrm{Ci} / \mathrm{ml}(0.1 \mu \mathrm{M}, 30.2 \mathrm{Ci} / \mathrm{mmol})\left[{ }^{3} \mathrm{H}\right] 2-\mathrm{DG}$ with or without $7 \mu \mathrm{g} / \mathrm{ml} \mathrm{AcLDL}$ or with $40 \mu \mathrm{l} \% \mathrm{vol} / \mathrm{vol}$ of glutaraldehyde fixed IgG-opsonized sheep erythrocytes (E[IgG]) (19). The coverslips were washed six times with cold PBS, and $\left[{ }^{3} \mathrm{H}\right] 2-\mathrm{DG}$ was assayed in a scintillation spectrometer.

To assess the effect of low and no glucose in the medium on mac- 
rophage ATP and creatine phosphate $(\mathrm{CrP})$ levels, macrophages were plated on 35-mm dishes, maintained in medium containing 0,1 , or $5 \mathrm{mM}$ glucose \pm oleic acid for $24 \mathrm{~h}$, washed three times with cold PBS, extracted with $500 \mu \mathrm{l}$ cold perchloric acid, and ATP and $\mathrm{CrP}$ were measured as described $(16,25)$.

\section{Results}

Absence of LPL and LPL $m R N A$ in LPL-KO macrophages from LO-MCK mice. LPL-expressing and LPL-KO macrophages were incubated for $3 \mathrm{~d}$ in medium containing $5 \mathrm{mM}$ glucose and $10 \%$ FBS. The medium was harvested and assayed for triglyceride lipolytic activity. Monoclonal antihuman LPL IgG (22) and polyclonal chicken anti-bovine milk LPL antibodies were used in the assay to confirm the absence of both human and mouse LPL. The medium from normal macrophages contained $\sim 10$ times more lipolytic activity than medium from LPL-KO macrophages (Fig. $1 A$ ). As expected, monoclonal anti-human LPL IgG did not inhibit the LPL activity in medium from normal macrophages (Fig. $1 A$ ), or the small amount of LPL activity in the medium from LPL-KO cells (data not shown). In contrast, polyclonal chicken antiLPL antiserum inhibited $>70 \%$ of the LPL activity in the medium from normal macrophages (Fig. $1 A$ ), but did not block the small amount of triglyceride-hydrolyzing activity in the medium of LPL-KO macrophages (not shown). We have not investigated further the residual triglyceride lipase activity in the medium from LPL-KO macrophages. These studies confirm that peritoneal macrophages from normal mice synthesize and secrete LPL, while macrophages from LPL-KO mice do not.

To confirm further the lack of LPL expression by LPL-KO macrophages, RNA was isolated from normal and LPL-KO macrophages, and was probed for human and mouse LPL mRNA by RT-PCR. Using the primers described in Methods, the expected PCR product from mouse LPL mRNA should be $310 \mathrm{bp}$, and the one from human LPL mRNA $410 \mathrm{bp}$. As shown in Fig. $1 B$, the 310-bp RT-PCR product characteristic of mouse LPL mRNA was not found in RNA extracted from LPL-KO macrophages (lane 1), but was detected in RNA from normal macrophages (lane 2) and from mouse epididymal fat (lane 3). A 410-bp RT-PCR product characteristic of human LPL mRNA was detected in THP-1 cells, which express human LPL (lane 4), but not in RNA from normal mouse macrophages (lane 5) or LPL-KO macrophages (lane 6). Therefore, the LPL-KO cells contained no mouse LPL mRNA, and the MCK promoter did not drive LPL expression in macrophages.

Effects of glucose and VLDL on phagocytosis. To test whether the amount of glucose and the presence of VLDL would affect phagocytosis, normal (LPL-expressing) and LPL$\mathrm{KO}$ macrophages were maintained for $2 \mathrm{~d}$ in medium containing 1 or $5 \mathrm{mM}$ glucose with or without added VLDL. VLDL approximately doubled the phagocytic index of normal macrophages maintained in medium containing $1 \mathrm{mM}$ glucose, $10 \%$ DFBS (Fig. 2, filled bars). In contrast, addition of VLDL had no stimulatory effect on $\mathrm{E}(\mathrm{IgG})$ ingestion by LPL-KO macrophages (Fig. 2, open bars). Since the glucose-deficient cells were cultured in DFBS, we assessed whether cells maintained in $5 \mathrm{mM}$ glucose, $10 \%$ DFBS differed from cells grown in FBS. They did not; in this experiment the cells in FBS had a phagocytic index of $1,129 \pm 278$, whereas those in DFBS had a phagocytic index of $1,011 \pm 358(P=0.34)$. Overall, these re-
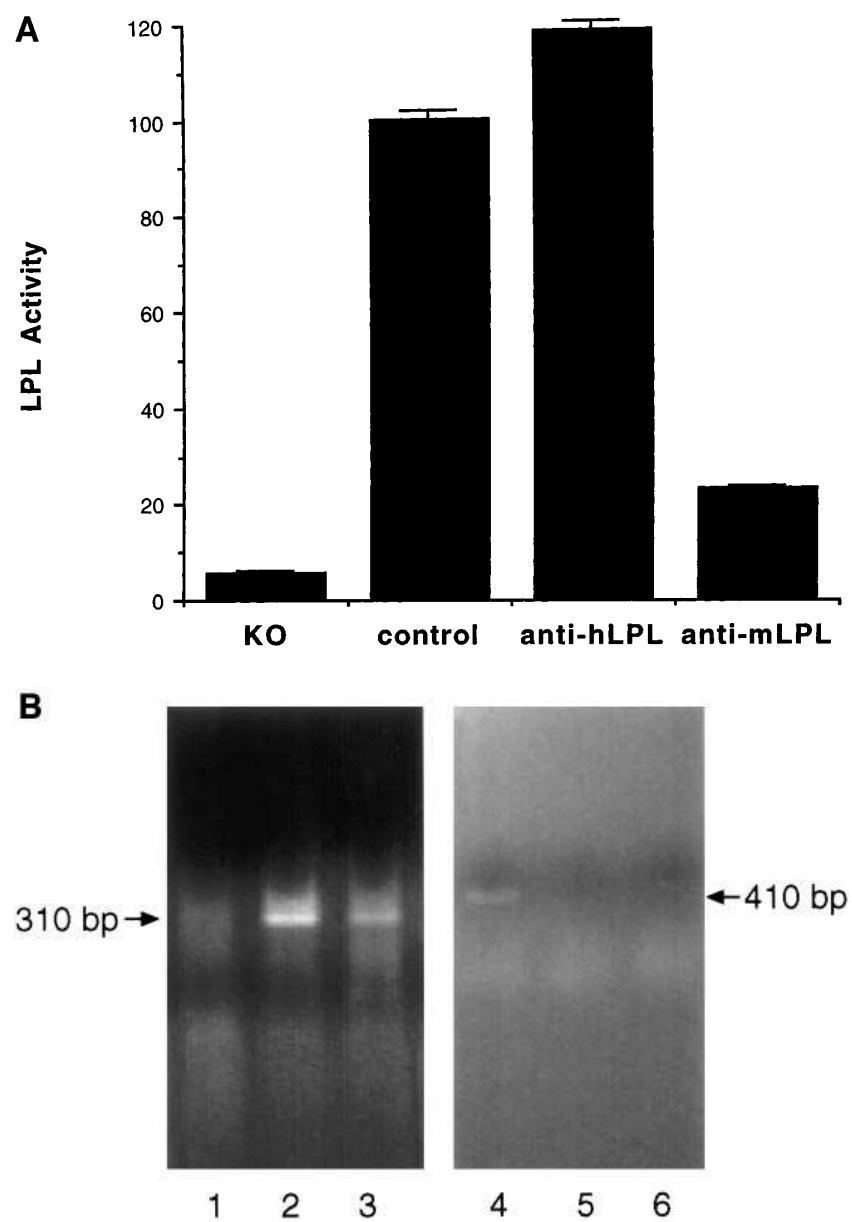

Figure 1. LPL expression in peritoneal macrophages from control and MCK-rescued LPL KO mice. ( $A$ ) Absence of LPL activity in culture medium from $\mathrm{KO}$ macrophages. Mouse peritoneal macrophages $\left(2 \times 10^{6}\right.$ cells/dish $)$ were cultured in DMEM containing $5 \mathrm{mM}$ glucose $+10 \%$ FBS for $3 \mathrm{~d}$. The medium was removed and the cells were incubated for $4 \mathrm{~h}$ at $37^{\circ} \mathrm{C}$ in $1 \mathrm{ml}$ of DMEM containing $5 \mathrm{mM}$ glucose and $0.5 \%$ BSA. To release membrane-bound LPL, $0.5 \mathrm{U} / \mathrm{ml}$ heparin was added to the medium $10 \mathrm{~min}$ before its collection. The amount of LPL in the medium was assayed with antibodies against mouse (anti-LPL) or human LPL (anti-human LPL). The bars represent the mean value $\pm \mathrm{SD}$ of three experiments expressed as percent control macrophage LPL activity $(100 \%$ activity $=0.13 \mu \mathrm{mol} \mathrm{FFA} / \mathrm{h} /$ $\mathrm{mg}$ cell protein). (B) Absence of LPL mRNA in LPL-KO macrophages as determined by RT-PCR. Total RNA was isolated from the cells, and RT-PCR was performed as described in Methods. For mouse LPL, the 310-bp fragment of the mouse LPL gene was not amplified in LPL-KO macrophages (lane 1), but was detected in normal macrophages (lane 2) and in normal mouse epididymal fat (lane 3). For human LPL, the predicted 410-bp product was found only in THP-1 macrophages expressing human LPL (lane 4), but not in normal (lane 5) or LPL-KO mouse macrophages (lane 6).

sults suggest that fatty acids generated by LPL hydrolysis of VLDL provide fuel for phagocytosis.

In contrast to the effects on phagocytosis found in cells maintained in low glucose, the presence of LPL expression and VLDL had relatively minor effects on the phagocytic index of cells maintained in medium containing $5 \mathrm{mM}$ glucose. The higher glucose concentration increased the phagocytic index of LPL-expressing macrophages almost threefold. LPL-KO mac- 


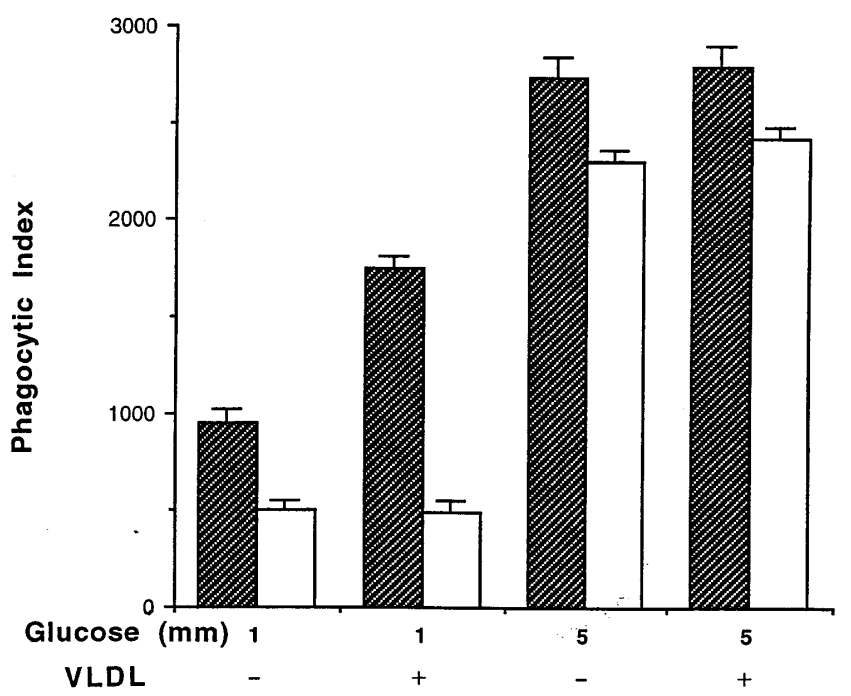

Figure 2. Effects of VLDL on the phagocytosis of IgG-opsonized RBC by LPL-expressing (control) and LPL-KO macrophages. Mouse peritoneal macrophages were plated on coverslips in 24-well plates, and were cultured in DMEM containing $1 \mathrm{mM}$ glucose $+10 \%$ DFBS or DMEM containing $5 \mathrm{mM}$ glucose $+10 \%$ FBS with $(+)$ or without $(-)$ VLDL $(100 \mu \mathrm{g} / \mathrm{ml})$ for $48 \mathrm{~h}$. Cells were then incubated in PBS containing $1 \mathrm{mM}$ glucose and $1 \% \mathrm{vol} / \mathrm{vol} \mathrm{E}(\mathrm{IgG})$ for $1 \mathrm{~h}$ at $37^{\circ} \mathrm{C}$. The numbers of RBC in 100 cells on each coverslip were then counted microscopically. The bars represent the mean value \pm SD of triplicates. White bars, knockout; striped bars, control.

rophages had a more than fourfold increase in phagocytic index when incubated in $5 \mathrm{mM}$ rather than in $1 \mathrm{mM}$ glucose, and under these conditions the LPL-KO macrophages phagocytosed $85 \%$ as many $\mathrm{E}(\mathrm{IgG})$ as LPL-expressing macrophages. In the presence of VLDL and $5 \mathrm{mM}$ glucose, neither LPLexpressing or LPL-KO macrophages had a significant increase in phagocytosis of $\mathrm{E}(\mathrm{IgG})$. Glucose, therefore, potentiated macrophage phagocytosis. VLDL had no effect on phagocytosis in the presence of $5 \mathrm{mM}$ glucose. Thus, VLDL augmented phagocytosis only under glucose limiting conditions.

Effect of oleate on phagocytosis. To test the hypothesis that fatty acids stimulate phagocytosis by cells maintained in low glucose, we assessed $\mathrm{E}(\mathrm{IgG})$ ingestion by LPL-expressing and LPL-KO macrophages maintained in low glucose medium supplemented with oleic acid $(0.4 \mathrm{mM})$, or with VLDL. Oleic acid supplementation increased $\mathrm{E}(\mathrm{IgG})$ phagocytosis by LPLexpressing macrophages 2-3.7-fold (Fig. $3 A$ ), and by LPL-KO macrophages 3.4-fold (Fig. 3 B). As shown in Fig. 2 and in Fig. $3 A$, addition of VLDL increased $\mathrm{E}(\mathrm{IgG})$ phagocytosis by LPL-expressing macrophages threefold, but was without effect in LPL-KO macrophages (Fig. 3 B). The phagocytosis stimulatory effect of VLDL in LPL-expressing macrophages was inhibited $\sim 50 \%$ by tetrahydrolipstatin (THL), an LPL inhibitor (26). Complete inhibition of the VLDL effect was not observed because the THL, a competitive inhibitor, may not be completely effective in blocking LPL activity, or because LPL continued to mediate uptake of some VLDL via nonenzymatic processes $(27,28)$. As expected, THL had no effect on phagocytosis by LPL-KO macrophages (Fig. 3 B). Taken together, these data further support the hypothesis that VLDL stimu-
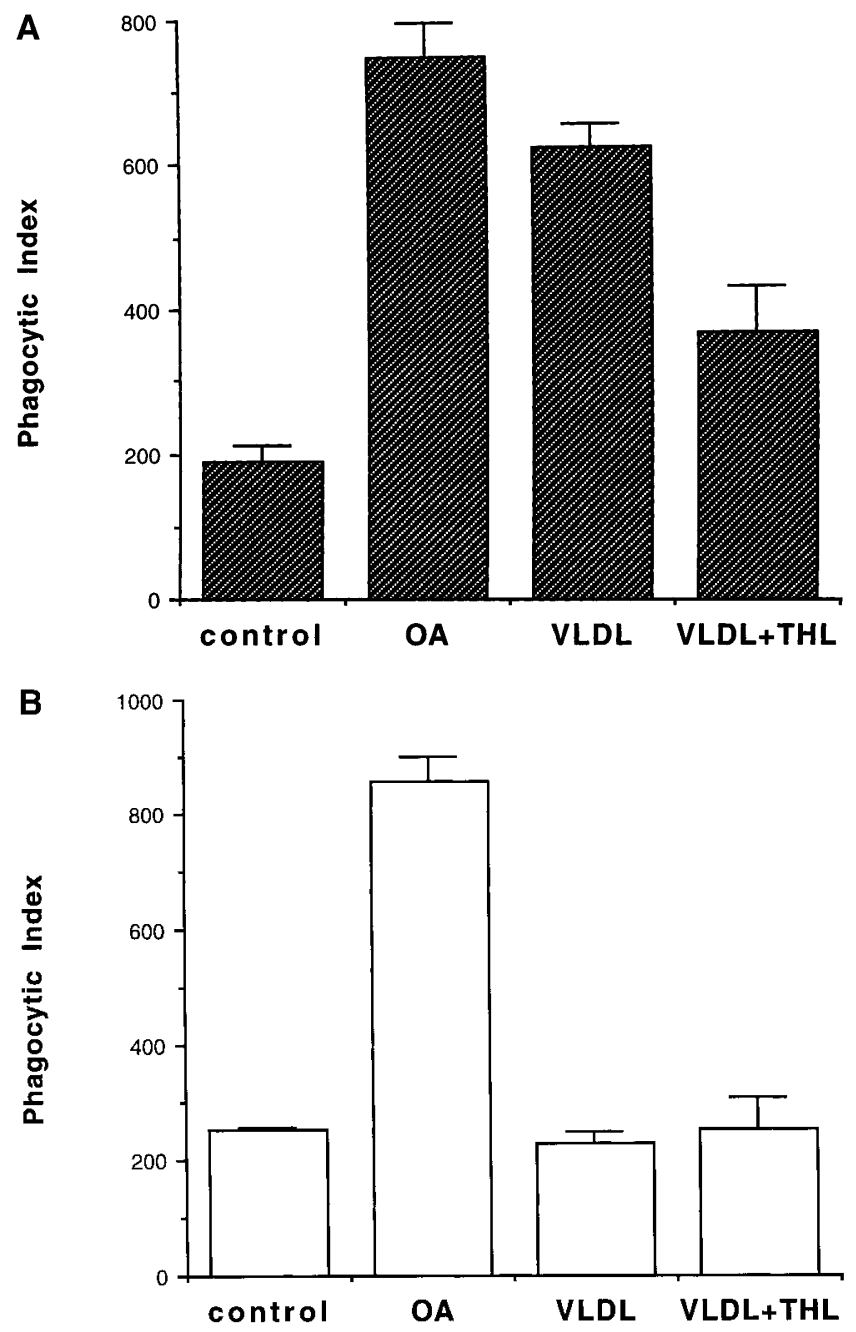

Figure 3. Effects of oleic acid $(O A)$ and THL on phagocytosis of IgG-opsonized RBC by macrophages. Mouse peritoneal macrophages from normal mice $(A)$ or L0-MCK mice $(B)$ were plated on coverslips and cultured in DMEM containing $1 \mathrm{mM}$ glucose $+10 \%$ FBS. $0.4 \mathrm{mM}$ of OA or $100 \mu \mathrm{g} / \mathrm{ml}$ of VLDL was added as indicated. 0.1 mM THL (Hoffman-La Roche, Basel, Switzerland), an LPL inhibitor, was added to the medium by appropriate dilution of a THL stock solution $(24 \mathrm{mM})$ in dimethylsulfoxide. These conditions are designated VLDL + THL. The bars represent the mean value \pm SD of triplicate samples.

lates $\mathrm{E}(\operatorname{IgG})$ uptake by LPL-expressing macrophages by providing an LPL-releasable source of fatty acids.

To test further whether oleate could augment phagocytosis by glucose-deprived cells, we compared phagocytosis in cells maintained for $48 \mathrm{~h}$ in $0 \mathrm{mM}$ glucose \pm oleate. Under these conditions, phagocytosis was stimulated markedly by oleic acid; the phagocytic index was only $88 \pm 51$ without oleate, and $865 \pm 260$ in oleic acid-containing medium $(P=0.014)$. In addition, we assessed whether acute addition of oleic acid would increase phagocytosis. To do this, cells were maintained for $48 \mathrm{~h}$ in $0 \mathrm{mM}$ glucose, and the oleic acid was added during a subsequent 1-h incubation in PBS-FBS. The $\mathrm{E}(\mathrm{IgG})$ were then added, and phagocytosis was allowed to occur. The phagocytic index was greater in the presence of oleic acid, and increased 
Table I. Effects of Metabolic Inhibitors on Phagocytic Index

\begin{tabular}{llc}
\hline Medium & Inhibitor & Phagocytic index \\
\hline 5 & None & $>2000$ \\
$5+$ & None & $>2000$ \\
1 & None & $490 \pm 120$ \\
$1+$ & None & $1160 \pm 194$ \\
1 & $\mathrm{NaF}$ & $325 \pm 32$ \\
$1+$ & $\mathrm{NaF}$ & $640 \pm 42$ \\
1 & $\mathrm{NaN}_{3}$ & $630 \pm 155$ \\
$1+$ & $\mathrm{NaN}_{3}$ & $535 \pm 150$ \\
\end{tabular}

Peritoneal macrophages from LPL-expressing mice $\left(5 \times 10^{5} /\right.$ coverslip $)$ were cultured in DMEM containing $10 \%$ DFBS and 1 or $5 \mathrm{mM}$ glucose $(5 \mathrm{mM})$ with or without added oleic acid for $48 \mathrm{~h}$. The indicated metabolic inhibitors $\left(0.25 \mathrm{mM} \mathrm{NaF}\right.$ or $\left.1.0 \mathrm{mM} \mathrm{NaN}_{3}\right)$ were added to the media, and $48 \mathrm{~h}$ later phagocytosis of $\mathrm{E}(\mathrm{IgG})$ was assessed during $1 \mathrm{~h}$ at $37^{\circ} \mathrm{C}$. Phagocytosis of $\mathrm{E}(\mathrm{IgG})$ was assessed as described in Methods. The values given are the mean $\pm \mathrm{SD}$ of the number of $\mathrm{E}(\mathrm{IgG})$ per 100 cells. $5=$ DMEM containing $5 \mathrm{mM}$ glucose; $1=$ DMEM containing 1 $\mathrm{mM}$ glucose. + signifies addition of $0.4 \mathrm{mM}$ oleic acid.

almost to the level seen with the more chronic oleic acid, $816 \pm 14$; this increase over the oleic acid-deficient condition was statistically significant at $P=0.012$. Therefore, as expected, the effects of oleate addition were even more dramatic in cells that were totally glucose deficient.

Since oleic acid augmented the phagocytic index of macrophages maintained in $1 \mathrm{mM}$ glucose, we examined the oleate effect in the presence of an inhibitor of glycolysis, $\mathrm{NaF}$, and an inhibitor of oxidative metabolism, azide. As expected (Table I), the phagocytic index of cells treated with $0.25 \mathrm{mM} \mathrm{NaF}$ was reduced by $>30 \%$. When $\mathrm{NaF}$ was added to cells preincubated for $2 \mathrm{~d}$ in oleic acid, the phagocytic index was nearly twofold greater than that of cells maintained in the absence of oleic acid. Oleic acid, however, was unable to compensate fully for the inhibition of glycolysis on phagocytosis. Cells treated with $1.0 \mathrm{mM} \mathrm{NaN}$ had a similar phagocytic index to cells grown in $1 \mathrm{mM}$ glucose alone. Oleic acid addition did not increase the phagocytic index of $\mathrm{NaN}_{3}$-treated cells. Therefore, inhibition of oxidative metabolism, but not glycolysis, blocked the oleate stimulation of phagocytosis. These data are consistent with the hypothesis that oleic acid is metabolized to provide energy for cells, thereby enhancing phagocytosis.

Effect of inhibition of LPL on E(IgG) phagocytosis by THP-1 cells. To examine the role of LPL in human macrophages, we maintained THP-1 cells, a human macrophage-like cell line, in medium containing $1 \mathrm{mM}$ glucose with and without VLDL. VLDL stimulated E(IgG) phagocytosis in THP-1 macrophages maintained in $1 \mathrm{mM}$ glucose about 1.5 -fold (Fig. 4 , solid bars). The stimulatory effect of VLDL was completely abolished by pretreatment of THP-1 cells with anti-human LPL IgG (Fig. 4, open bars), an antibody that blocks the interactions of LPL with VLDL (22). These results confirm that LPL is essential for VLDL to stimulate phagocytosis of $\mathrm{E}(\mathrm{IgG})$ in human macrophages. They provide additional evidence that macrophages use fatty acids as an alternative fuel source under conditions where glucose is limiting. It should be noted that anti-LPL IgG also had a small inhibitory effect $(\sim 15 \%)$ on $\mathrm{E}(\mathrm{IgG})$ ingestion by THP-1 cells maintained in medium lacking added VLDL. Whether the antibody blocked

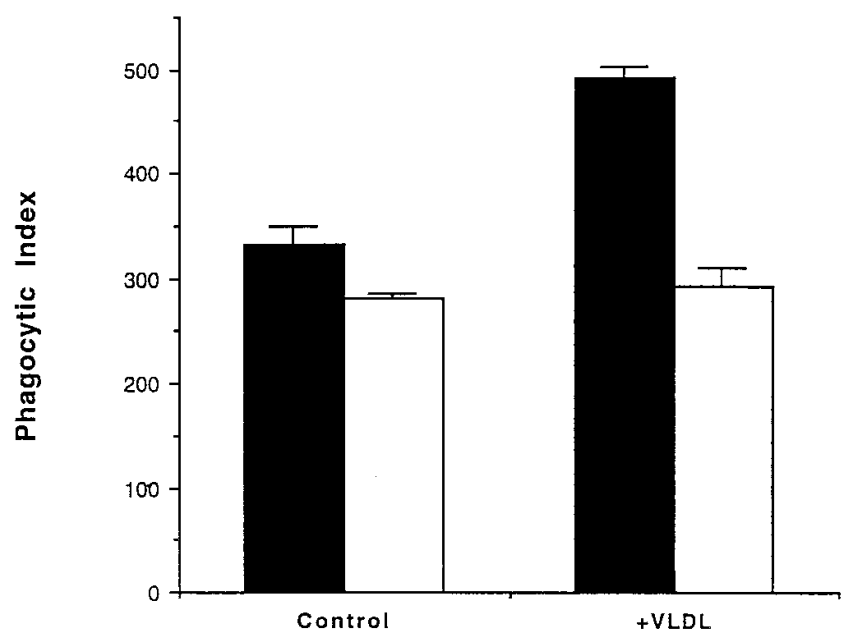

Figure 4. Effect of anti-human LPL IgG on phagocytosis by human macrophages. THP- 1 cells were cultured at $0.5 \times 10^{6}$ cells/coverslip in RPMI containing $10 \%$ FBS and $1.6 \times 10^{-7} \mathrm{M}$ phorbal myristic acetate for $48 \mathrm{~h}$ to promote their differentiation into macrophages. The cells then were incubated for an additional $48 \mathrm{~h}$ in RPMI containing 1 $\mathrm{mM}$ glucose and $10 \%$ DFBS with $(+)$ or without added VLDL, and with (white bar) or without (black bar) anti-human LPL monoclonal antibody. The cells were washed and incubated in PBS containing 1 $\mathrm{mM}$ glucose and $1 \% \mathrm{vol} / \mathrm{vol} \mathrm{E}(\mathrm{IgG})$ for $1 \mathrm{~h}$ at $37^{\circ} \mathrm{C}$. The number of RBC ingested per 100 THP-1 cells on each coverslip was then counted microscopically. Bars represent the mean value \pm SD of triplicate samples. Black bar, $-\mathrm{Ab}$; white bar, $+\mathrm{Ab}$.

LPL-catalyzed lipolysis of the small amount of lipoproteins in FBS or had a minor inhibitory effect on the interaction of $\mathrm{E}(\mathrm{IgG})$ with $\mathrm{Fc}$ receptors is unknown.

$1 \mathrm{mM}$ glucose did not affect macrophage receptor-mediated endocytosis. To determine whether limiting glucose affects other forms of macrophage endocytosis besides Fc receptormediated phagocytosis, we examined receptor-mediated endocytosis of DiI-AcLDL, a particle whose uptake in macrophages is mediated by type A scavenger receptors $(29,30)$. In contrast to phagocytosis of E(IgG), LPL-expressing and LPL$\mathrm{KO}$ macrophages internalized equal amounts of DiI-AcLDL whether maintained in medium containing 5 or $1 \mathrm{mM}$ glucose, and in the presence or absence of VLDL (Fig. 5). Glucosedeficient $(1 \mathrm{mM})$ medium also did not reduce DiI-AcLDL uptake by THP-1 cells (data not shown).

We also examined the effects of medium containing $1 \mathrm{mM}$ glucose with and without VLDL on receptor-mediated endocytosis of ${ }^{125} \mathrm{I}$-oxLDL by LPL-expressing and LPL-KO macrophages. As with DiI-AcLDL (Fig. 5), lowering medium glucose to $1 \mathrm{mM}$ and addition of VLDL had no effect on ${ }^{125} \mathrm{I}$-ox LDL uptake by normal or LPL-KO macrophages (data not shown). Thus, receptor-mediated endocytosis, unlike Fc receptor-mediated phagocytosis, is insensitive to limited availability of glucose and fatty acids in the medium.

ATP and CrP content of macrophages maintained in glucose-deficient medium with or without oleic acid. Because oleic acid augmented phagocytosis (an energy-requiring process), we assessed whether macrophages had a difference in intracellular forms of stored energy when the cells were maintained in media containing added fatty acid. Oleic acid addition led to no significant changes in $\mathrm{CrP}$ and ATP in macrophages main- 


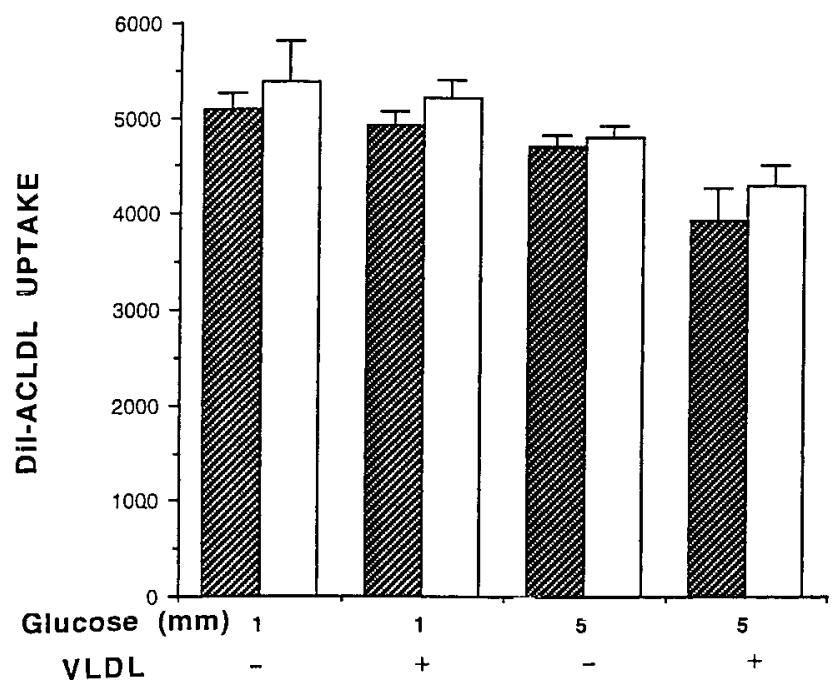

Figure 5. Effects of glucose and VLDL on endocytosis of AcLDL by control (LPL-expressing) and LPL-KO mouse macrophages. Mouse peritoneal macrophages were cultured on 12-well plates with $2 \times 10^{6}$ cells/well for $48 \mathrm{~h}$ in DMEM containing $1 \mathrm{mM}$ glucose $+10 \%$ DFBS, or DMEM containing $5 \mathrm{mM}$ glucose $+10 \%$ FBS with or without 100 $\mu \mathrm{g} / \mathrm{ml}$ VLDL. Cells were then incubated for $2 \mathrm{~h}$ in $500 \mu \mathrm{l}$ of serumless DMEM containing $1 \mathrm{mM}$ glucose, $0.3 \%$ BSA, and $3.5 \mu \mathrm{g}$ DiI-AcLDL. Membrane-bound AcLDL was released by incubating the cells in the same medium containing $100 \mathrm{U} / \mathrm{ml}$ heparin for $15 \mathrm{~min}$. Internalized DiI was extracted with $200 \mu \mathrm{l}$ methanol and quantitated by fluorescence. Striped bar, control; white bar, knockout.

tained in $5 \mathrm{mM}$ glucose (Fig. 6). In contrast, when the cells were glucose-deprived, intracellular energy stores were greater if oleic acid was included during the incubation. As expected, this effect was seen most dramatically in the cells maintained in $0 \mathrm{mM}$ glucose. $\mathrm{CrP}$ doubled in these cells at 6 and $24 \mathrm{~h}(\mathrm{CrP}$ from $0.22 \pm 0.07 \mathrm{nmol} / \mathrm{mg}$ protein in $0 \mathrm{mM}$ glucose to $0.52 \pm$ $0.10 \mathrm{nmol} / \mathrm{mg}$ protein with oleate, $P=0.028$ ). Despite this result, $\mathrm{CrP}$ was still only half of that of cells grown in $5 \mathrm{mM}$ glucose, which averaged $1.03 \pm 0.23 \mathrm{nmol} / \mathrm{mg}$ protein. These changes in energy stores paralleled the stimulation of phagocytosis under these conditions (see above) where oleic acid markedly increased phagocytosis in glucose-deprived cells, but did not restore it to the levels observed in $5 \mathrm{mM}$ glucose. Smaller increases in both ATP and CrP (25-36\%) were found when oleic acid was added to cells maintained in $1 \mathrm{mM}$ glucose (data not shown). Therefore, oleic acid increased the amounts of intracellular high-energy phosphate stores of glucosedeprived cells.

A second method used to assess whether oleic acid substituted for glucose in cellular metabolism was to determine glucose consumption in control versus oleic acid-supplemented cells. To do this, the residual amounts of glucose in the media at the end of the 48-h incubations were assessed. Cells grown in $1 \mathrm{mM}$ glucose plus oleic consumed approximately one-third as much glucose as did cells cultured with no oleic acid. The residual glucose at the end of the 48-h incubation was $0.21 \pm 0.02$ $\mathrm{mM}$ in media from cells cultured in $1 \mathrm{mM}$ glucose DMEM, and $0.35 \pm 0.07 \mathrm{mM}$ in cells cultured in $1 \mathrm{mM}$ glucose DMEM plus oleic acid $(P=0.012)$. In contrast, addition of oleic acid to cells grown in $5 \mathrm{mM}$ glucose media plus 10\% DFBS led to no
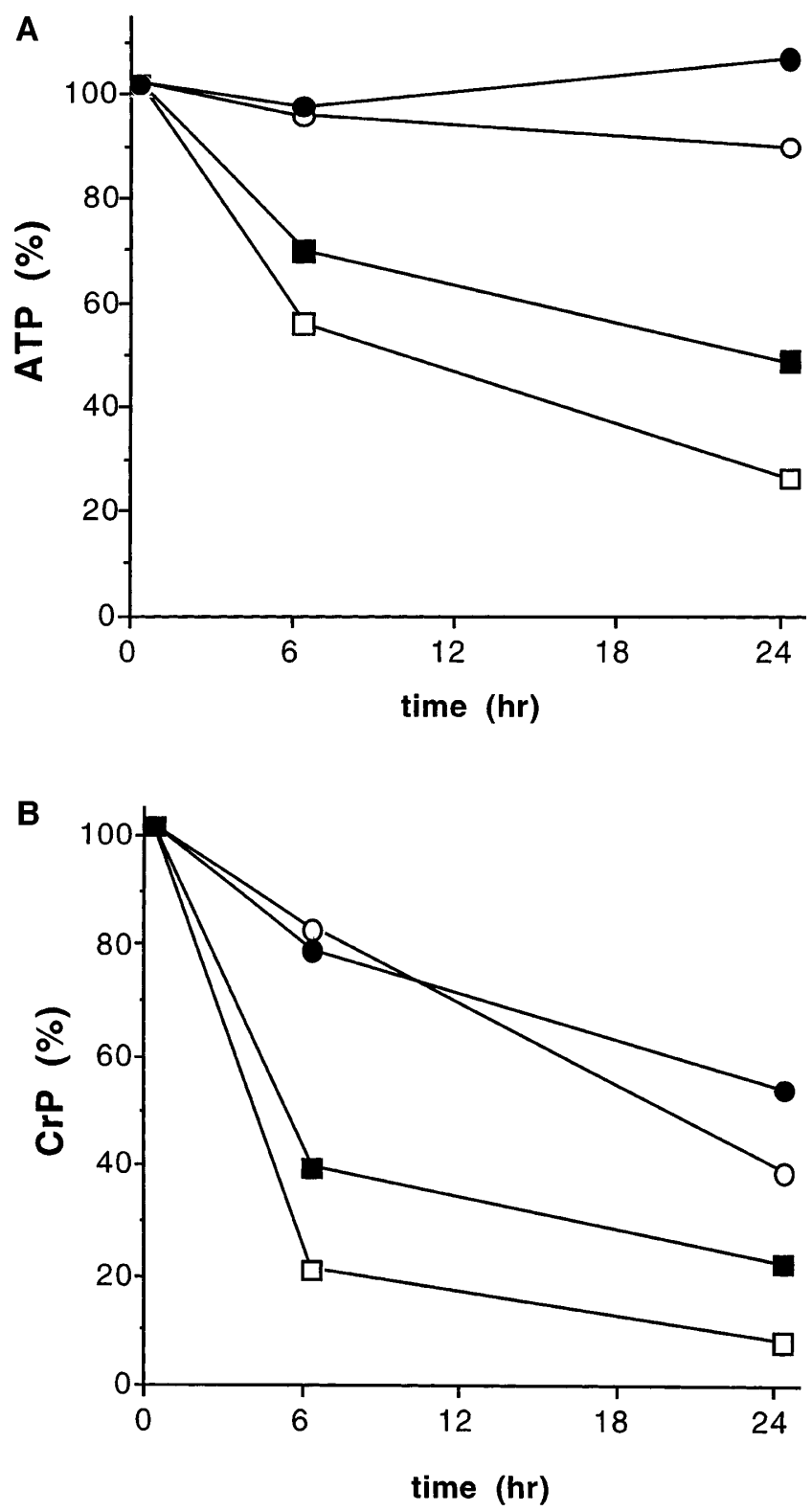

Figure 6. Cellular energy stores in cells grown in 0 or $5 \mathrm{mM}$ glucose with or without oleic acid. Peritoneal macrophages $\left(2 \times 10^{6} / 35 \mathrm{~mm}\right.$ dish) were culture in DMEM containing 0 or $5 \mathrm{mM}$ glucose $+10 \%$ DFBS with or without oleic acid $(0.4 \mathrm{mM})$ for up to $24 \mathrm{~h}$, and ATP and $\mathrm{CrP}$ levels were measured as described in Methods at 0, 6, and $24 \mathrm{~h}$ of incubation. The values represent the mean of duplicate wells with each value measured in triplicate. Control values (time 0 ) for ATP and $\mathrm{CrP}$ were 0.45 and $1.40 \mathrm{nmol} / \mathrm{mg}$ cell protein. Open square, $0 \mathrm{mM}$; closed square, $0 \mathrm{mM}+\mathrm{OA}$; open circle, $5 \mathrm{mM}$; closed circle, 5 $\mathrm{mM}+\mathrm{OA}$.

differences in glucose consumption; the final glucose concentrations were $3.09 \pm 0.24$ in oleic acid-treated cells versus $3.34 \pm 0.17$ in cells receiving no fatty acid $(P=0.11)$. Therefore, addition of oleic acid spared glucose, but only under glucoselimited conditions.

Phagocytosis, but not receptor-mediated endocytosis, stimulates 2-DG uptake and accumulation. Fc receptor ligation stimulates macrophage glucose uptake and metabolism (1). There 


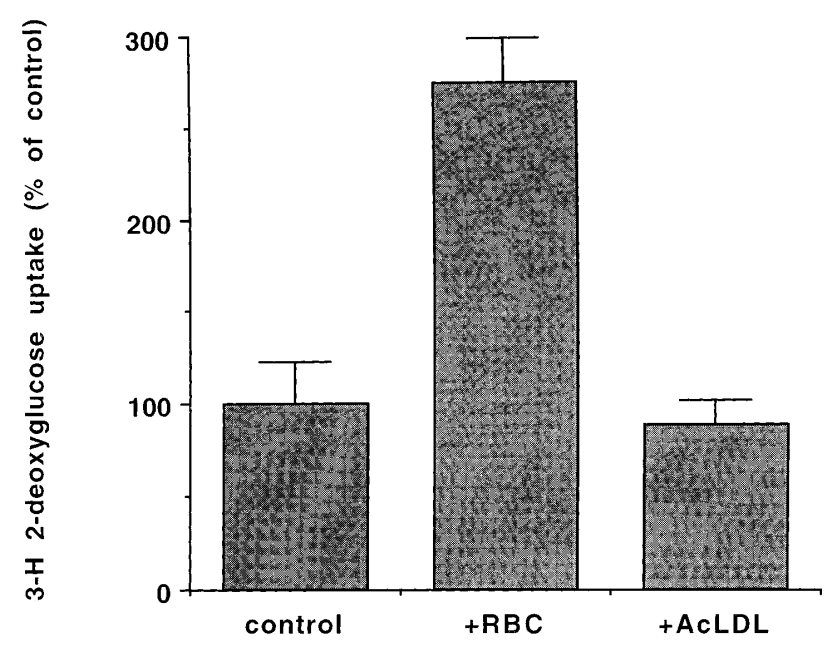

Figure 7. Effects of phagocytosis and endocytosis on 2-DG uptake by normal mouse macrophages. Mouse peritoneal macrophages were cultured on coverslips on 24-well plates at $10^{6}$ cells/coverslip in DMEM containing $1 \mathrm{mM}$ glucose and 10\% FBS for $48 \mathrm{~h}$. Cells were then incubated for $1 \mathrm{~h}$ in DMEM containing $1 \mathrm{mM}$ glucose, $0.3 \%$ BSA, $0.1 \mu \mathrm{M}$ of $\left[{ }^{3} \mathrm{H}\right] 2-D G$ with or without $7 \mu \mathrm{g} / \mathrm{ml}$ of AcLDL or $1 \%$ vol/vol of glutaraldehyde-treated RBC. Cells were washed with PBS extensively, and the uptake of $\left[{ }^{3} \mathrm{H}\right] 2-\mathrm{DG}$ was quantitated. The bars represent the mean $\pm \mathrm{SD}$ of triplicate samples. The control value was $1.2 \mathrm{nmol} / \mathrm{h} / \mathrm{mg}$ protein.

are no comparable data on effects of ligation of macrophage scavenger receptors. Therefore, we compared the effects of Fc receptor-mediated phagocytosis of $\mathrm{E}(\mathrm{IgG})$ and scavenger receptor-mediated endocytosis of DiI-AcLDL on $\left[{ }^{3} \mathrm{H}\right] 2-\mathrm{DG}$ uptake by LPL-expressing and LPL-KO macrophages maintained in media containing $1 \mathrm{mM}$ glucose. Receptor-mediated endocytosis of DiI-AcLDL had no effect on macrophage uptake and accumulation of $\left[{ }^{3} \mathrm{H}\right] 2-\mathrm{DG}$, while phagocytosis of $\mathrm{E}(\mathrm{IgG})$ stimulated macrophage $\left[{ }^{3} \mathrm{H}\right] 2-\mathrm{DG}$ uptake 2.7-fold (Fig. 7). In these experiments, the sheep RBC were pretreated with $2.5 \%$ glutaraldehyde to eliminate their capacity to internalize 2-DG. Previous studies (31) showed that glutaraldehyde-fixed RBC behave similarly to untreated RBC with respect to ingestion via $\mathrm{Fc}$ receptors.

\section{Discussion}

This report provides the first evidence that fatty acids fuel phagocytosis by macrophages under conditions of relative glucose deprivation, and that LPL produced by macrophages plays an essential role in this process by releasing fatty acids from extracellular lipoproteins. Several lines of evidence support these conclusions. First, LPL-expressing and LPL-KO peritoneal macrophages maintained for $48 \mathrm{~h}$ under conditions of relative glucose deficiency ( $1 \mathrm{mM}$ glucose) did not phagocytose as efficiently as the same macrophages maintained in glucose-sufficient medium (5 mM glucose) (Fig. 2). Addition of VLDL to the glucose-deficient medium enhanced E(IgG) phagocytosis by LPL-expressing, but not LPL-KO, macrophages. Second, supplementation of glucose-deficient medium with oleate stimulated phagocytosis by both LPL-expressing and LPL-KO macrophages between 2- and 3.7-fold (Table I, Fig. 3). Third, the phagocytosis-promoting effect of VLDL on
LPL-expressing macrophages was abolished by anti-LPL antibodies (Fig. 4) and by the LPL inhibitor THL (Fig. 3). Fourth, the capacity of oleate to stimulate phagocytosis by macrophages maintained in $1 \mathrm{mM}$ glucose was abolished by an inhibitor of oxidative phosphorylation $\left(\mathrm{NaN}_{3}\right)$ but not by an inhibitor of glycolysis (NaF, Table I). Fifth, studies performed using cells grown in $0 \mathrm{mM}$ glucose showed that oleic acid acutely stimulates phagocytosis and increases cellular CrP.

Newsholme and colleagues $(2,32)$ found that oxidation of oleate accounts for between 22 and $38 \%$ of ATP generation by resting thioglycollate-elicited mouse peritoneal macrophages. This finding prompted them to suggest that long-chain fatty acids might be an important fuel source for macrophages, and that LPL secreted by macrophages might generate these fatty acids from lipoproteins in the extracellular milieu. The data reported here provide strong support for their hypothesis.

The reason that we were able to observe the dependency of macrophages on fatty acid-derived energy is that, unlike most previous studies $(1,32)$, we maintained macrophages in hypoglycemic conditions. Unlike the studies by Speert and Gordon (4) that suggest that pseudomonas are not ingested in the absence of glucose, we specifically examined the role of fatty acid metabolism in IgG-dependent phagocytosis. Our results are most relevant to macrophages that reside and function for prolonged periods of time in tissue compartments where glucose is limited.

Several other roles have been proposed for macrophage LPL (13). First, it was proposed that macrophage LPL was required to catabolize large, triglyceride-rich lipoproteins, thereby facilitating macrophage uptake of these partially degraded lipoproteins and leading to lipid storage and foam cell development (7-9). Second, studies by our group $(27,33,34)$ and others (35-37) have shown that LPL can function as an adhesion molecule. Since LPL contains a heparin binding site and a lipid-binding lid region (12), it can form a bridge between cells and lipoproteins. By increasing lipoprotein association with the cell surface, LPL can increase lipoprotein uptake by nonenzymatic processes $(34,38)$. Moreover, LPL can serve as a cell-cell adhesion molecule (39) because enzymatically active LPL is a dimer and can simultaneously link proteoglycans on two different cells, e.g., monocytes and endothelial cells. A third function of macrophage LPL relates to the uptake of fatsoluble vitamins by these cells. LPL has been shown to promote cellular uptake of vitamins A and E $(40,41)$, thereby regulating the amount of these antioxidant and differentiation vitamins.

Our data show that fatty acids generated by the actions of LPL provide an important fuel for macrophages. We showed that LPL inhibitors partially (Fig. 3), or completely (Fig. 4), blocked the capacity of VLDL to stimulate phagocytosis by LPL-expressing macrophages. These inhibitors, however, had no effect on the capacity of oleate to stimulate phagocytosis. These findings indicate that secreted LPL must hydrolyze lipoproteins extracellularly for macrophages to obtain sufficient fatty acids to promote phagocytosis. They strongly suggest that macrophages do not endocytose sufficient lipoproteins from the medium and/or hydrolyze sufficient lipoproteins intracellularly to provide comparable amounts of fatty acids.

Energy requirements of macrophages are unique for this type of white blood cell. Within the bloodstream and near the vasculature, monocytes are in the presence of a sufficient amount of glucose to maintain their cellular functions. Mono- 
cytes do not express LPL; as monocytes differentiate into macrophages, however, LPL is expressed $(12,42)$. The energy requirements of macrophages change markedly when they are activated. Moreover, as shown previously (16), macrophages use more energy during phagocytosis. This effect would be likely to occur while combating infections and removing debris in damaged tissues. Macrophages are often functional and most important in regions that have suboptimal blood perfusion. These regions include abscess cavities, ischemic tissues, and the alveolar space. Several LPL substrates from which fatty acids could be generated are found in these sites. These include lipoproteins, and the triglyceride and phospholipids that are components of the membranes of cells and microorganisms.

The atherosclerotic plaque might also be an energy-limited environment for the macrophage. Within a more advanced plaque, these cells are often located in lipid-rich regions surrounded by dense connective tissue. The exact conditions found within the center of these lesions are difficult to know for certain, and the extent to which glucose permeates these zones is unknown. Macrophages within atherosclerotic lesions express LPL $(43,44)$. We propose that within these lesionswhere macrophages proliferate, differentiate, and phagocytose cell debris-LPL plays a major role in meeting the high energy demands of the cells.

Fatty acids appear to be used differently in macrophages than other cells such as adipocytes and myocytes. Adipocytes use fatty acids to assemble and store triglycerides that in times of need are hydrolyzed to produce fatty acids used for energy by other cells $(45,46)$. In contrast, myocytes continually use fatty acids as a primary energy source for contractile events. Exercising skeletal muscle uses both glucose and fatty acids, however, when glycogen stores are depleted almost all energy is provided by fatty acid metabolism $(47,48)$. The macrophage, possibly because of its peripatetic nature, has adopted a metabolic system that contains features of both the adipocyte and the myocyte. Although macrophages can store fatty acids as triglyceride (49), extracellular fatty acids do not, per se, modulate the intracellular storage forms of high-energy phosphates under normoglycemic conditions (Fig. 6). In our studies, hypoglycemia reduced macrophage energy stores. Macrophages maintained in medium containing $1 \mathrm{mM}$ glucose contained about half as much $\mathrm{CrP}$ as macrophages maintained in medium containing glucose at plasma concentrations (i.e., $5 \mathrm{mM}$ or $90 \mathrm{mg} / 100 \mathrm{ml}$ ); macrophages maintained in $0 \mathrm{mM}$ glucose had even less CrP. The addition of oleic acid stimulated phagocytosis by macrophages maintained in glucose-deficient medium, and this stimulation, at least in the totally glucose-deprived cells, paralleled the increase in $\mathrm{CrP}$. This result suggests that macrophages oxidize fatty acid stores to form high-energy phosphagens, but only when required by a glucose-limited environment.

Several other cells and tissues may use fatty acids in a similar fashion to that observed in the macrophage. In situ hybridization studies have shown high concentrations of LPL mRNA in hippocampal (50) and in spinal cord neurons (51). These cells may use LPL-derived fatty acids for metabolic energy since they function within the lower glucose concentrations in the cerebral spinal fluid, a possibility that could be most important during development or after injury, times when neuronal energy demands are greatest.

Another observation from our studies is that the energy re- quirements for receptor-mediated endocytosis and phagocytosis differ, and are consistent with a previous report that phagocytosis is more sensitive to inhibitors of ATP generation than is receptor-mediated endocytosis (52). We measured receptormediated endocytosis of modified lipoproteins that are internalized by different classes of scavenger receptors $(23,29,30)$. Maintenance of macrophages in 1 and $5 \mathrm{mM}$ glucose did not alter lipoprotein uptake by the cells. Also, addition of an alternative energy source, fatty acids, did not increase receptormediated endocytosis. Further support for the hypothesis that receptor-mediated endocytosis and phagocytosis differ in their metabolic needs was obtained by assessing changes in glucose uptake during these two processes. Phagocytosis, but not receptor-mediated endocytosis, augmented the uptake of 2-DG by the cells. Thus, our data are consistent with the hypothesis that receptor-mediated endocytosis and phagocytosis in macrophages differ in their energy requirements.

Macrophages and myocytes express different isozymes of creatine kinase. For example, murine peritoneal macrophages express primarily the brain form of creatine kinase, and not the muscle or heart forms (25). Transgenic mice used in these studies were developed using a human LPL minigene driven by a muscle-specific promoter of creatine kinase. Our results show that human LPL was not expressed in macrophages from these transgenic mice, consistent with our hypothesis (16) that the MCK promoter is not expressed in the macrophage cell lineage, and that different promoter elements are required for creatine kinase expression in muscle and macrophages. Thus, either a second gene or different promoter elements are required for creatine kinase expression in these macrophages.

Our studies of macrophage functions need to be correlated with investigations of the role of macrophage LPL in vivo. Since humans (53) that are LPL deficient do not have obvious alterations in macrophage functions, it is likely that the fatty acids are a secondary or backup source of energy. Since LPLdeficient people have very high concentrations of circulating triglyceride, however, it may be that sufficient non-LPL-mediated triglyceride uptake by the cells occurs to provide the macrophages with fatty acids derived from intracellular triglyceride hydrolysis. Or, as likely occurs within the fat cells of these people, cellular metabolism is maintained by more glucose uptake.

\section{Acknowledgments}

The authors would like to thank Dr. David Severson for providing the THL used in these experiments and Dr. Joseph El Khoury for assisting with the endocytosis assays.

This study was supported by grants HL 21006 SCOR (B. Yin and I.J. Goldberg) and HL54591 (P.H. Weinstock, J.L. Breslow, and I.J. Goldberg) from the National Heart, Lung, and Blood Institute, by grant AI20516 from the National Institute of Allergy and Infectious Diseases, and a grant in aid from the American Heart Association, New York Affiliate (J.D. Loike and S.C. Silverstein).

\section{References}

1. Oren, R., A.E. Farnham, K. Saito, E. Milofsky, and M.L. Karnovsky. 1963. Metabolic patterns in three types of phagocytizing cells. J. Cell Biol. 17: 487-501.

2. Newsholme, P., S. Gordon, and E.A. Newsholme. 1987. Rates of utilization and fates of glucose, glutamine, pyruvate, fatty acids and ketone bodies by mouse macrophages. Biochem. J. 242:631-636.

3. Loike, J.D., E. Kaback, S.C. Silverstein, and T.H. Steinberg. 1993. Lac- 
tate transport in macrophages. J. Immunol. 150:1951-1958.

4. Speert, D.P., and S. Gordon. 1992. Phagocytosis of unopsonized Pseudomonas aeruginosa by murine macrophages is a two-step process requiring glucose. J. Clin. Invest. 90:1085-1092.

5. Simon, L.M., S.G. Axline, B.R. Horn, and E.D. Robin. 1973. Adaptations of energy metabolism in the cultivated macrophage. J. Exp. Med. 138:14131425.

6. Newsholme, P., L.F. Costa Rosa, E.A. Newsholme, and R. Curi. 1996. The importance of fuel metabolism to macrophage function. Cell Biochem. Function. 14:1-10

7. Lindqvist, P., J.L. Ostlund-Lindqvist, J.L. Witztum, D. Steinberg, and J.A. Little. 1983. The role of lipoprotein lipase in the metabolism of triglyceride-rich lipoproteins by macrophages. J. Biol. Chem. 258:9086-9092.

8. Huff, M.W., A.J. Evans, C.G. Sawyez, B.M. Wolfe, and P.J. Nestel. 1991. Cholesterol accumulation in J774 macrophages induced by triglyceride-rich lipoproteins. Comparison of very low density lipoprotein from subjects with type III, IV, and V hyperlipoproteinemias. Arterioscler. Thromb. 11:221-233.

9. Evans, A.J., C.G. Sawyez, B.M. Wolfe, P.W. Connelly, G.F. Maguire, and M.W. Huff. 1993. Evidence that cholesteryl ester and triglyceride accumulation in J774 macrophages induced by very low density lipoprotein subfractions occurs by different mechanisms. J. Lipid Res. 34:703-717.

10. Eckel, R.H. 1989. Lipoprotein lipase: a multifunctional enzyme relevant to common metabolic diseases. N. Engl. J. Med. 320:1060-1068.

11. Domin, W.S., A. Chait, and S.S. Deeb. 1991. Transcriptional activation of the lipoprotein lipase gene in macrophages by dexamethasone. Biochemistry. 30:2570-2574

12. Khoo, J.C., E. Mahoney, and J.L. Witztum. 1981. Secretion of lipoprotein lipase by macrophages in culture. J. Biol. Chem. 256:7105-7108.

13. Goldberg, I.J. 1996. Lipoprotein lipase: central roles in lipoprotein metabolism and atherosclerosis. J. Lipid Res. 37:693-707.

14. Levak-Frank, S., H. Radner, A. Walsh, R. Stollberger, G. Knipping, G. Heofler, W. Sattler, P.H. Weinstock, J.L. Breslow, and R. Zechner. 1995. Muscle-specific overexpression of lipoprotein lipase causes a severe myopathy characterized by proliferation of mitochondria and peroxisomes in transgenic mice. J. Clin. Invest. 96:976-986.

15. Weinstock, P.H., C.L. Bisgaier, K. Aalto-Setala, H. Radner, R. Ramakrishnon, S. Levak-Frank, A.D. Essenberg, R. Zechner, and J.L. Breslow. 1995. Severe hypertriglyceridemia, reduced high density lipoprotein and neonatal death in lipoprotein lipase knockout mice. J. Clin. Invest. 96:2555-2568.

16. Loike, J.D., V.F. Kozler, and S.C. Silverstein. 1979. Increased ATP and creatine phosphate turnover in phagocytosing mouse peritoneal macrophages. J. Biol. Chem. 254:9558-9564.

17. Michl, J., D.J. Ohlbaum, and S.C. Silverstein. 1976. 2-Deoxyglucose selectively inhibits Fc and complement receptor-mediated phagocytosis in mouse peritoneal macrophages. I. Description of the inhibitory effect. J. Exp. Med. 144:1465-1483.

18. Saxena, U., L.D. Witte, and I.J. Goldberg. 1989. Release of endothelial cell lipoprotein lipase by plasma lipoproteins and free fatty acids. J. Biol. Chem. 264:4349-4355

19. Auwerx, J.H., S. Deeb, J.D. Brunzell, G. Wolfbauer, and A. Chait. 1989. Lipoprotein lipase gene expression in THP-1 cells. Biochemistry. 28:4563-4567.

20. Nilsson-Ehle, P., and M.C. Schotz. 1976. A stable, radioactive substrate emulsion for assay of lipoprotein lipase. J. Lipid Res. 17:536-541.

21. Goers, J.W., M.E. Pedersen, P.A. Kern, J. Ong, and M.C. Schotz. 1987. An enzyme-linked immunoassay for lipoprotein lipase. Analt. Biochem. 166:2735 .

22. Goldberg, I., J. Paterniti, D. France, G. Martinelli, and J. Cornicelli. 1986. Production and use of a monoclonal antibody to human lipoprotein lipase. Biochim. Biophys. Acta. 878:168-176.

23. Sparrow, C.P., S. Parthasarathy, and D. Steinberg. 1989. A macrophage receptor that recognizes oxidized low density lipoprotein but not acetylated low density lipoprotein. J. Biol. Chem. 264:2599-2604.

24. Loike, J.D., L. Cao, J. Brett, S. Ogawa, S.C. Silverstein, and D. Stern. 1992. Hypoxia induces glucose transporter expression in endothelial cells. Am. J. Physiol. 263:C326-C333.

25. Loike, J.D., V.F. Kozler, and S.C. Silverstein. 1984. Creatine kinase expression and creatine phosphate accumulation are developmentally regulated during differentiation of mouse and human monocytes. J. Exp. Med. 159:746757.

26. Lookene, A., N. Skottova, and G. Olivecrona. 1994. Interaction of lipoprotein lipase with the active site inhibitor tetrahydrolipstatin (Orlistat). Eur. J. Biochem. 222:395-403.

27. Rumsey, S., J. Obunike, Y. Arad, R. Deckelbaum, and I. Goldberg. 1992. Lipoprotein lipase mediated uptake and degradation of low density lipoproteins by fibroblasts and macrophages. J. Clin. Invest. 90:1504-1512.

28. Chappell, D., G. Fry, M. Waknitz, L. Muhonen, M. Pladet, P. Iverius, and D. Strickland. 1993. Lipoprotein lipase induces catabolism of normal triglyceride-rich lipoproteins via the low density lipoprotein receptor-related protein/alpha 2-macroglobulin receptor in vitro. A process facilitated by cell-sur- face proteoglycans. J. Biol. Chem. 268:14168-14175.

29. Krieger, M., and J. Herz. 1994. Structures and functions of multiligand lipoprotein receptors: macrophage scavenger receptors and LDL receptorrelated protein (LRP). Annu. Rev. Biochem. 63:601-637.

30. El Khoury, J., C.A. Thomas, J.D. Loike, S.E. Hickman, L. Cao, and S.C. Silverstein. 1994. Macrophages adhere to glucose-modified basement membrane collagen IV via their scavenger receptors. J. Biol. Chem. 269:1019710200.

31. Loike, J.D., and S.C. Silverstein. 1983. A fluorescence quenching technique using trypan blue to differentiate between attached and ingested glutaraldehyde-fixed red blood cells in phagocytosing murine macrophages. J. Immunol. Methods. 57:373-379.

32. Newsholme, P., R. Curi, S. Gordon, and E.A. Newsholme. 1986. Metabolism of glucose, glutamine, long-chain fatty acids and ketone bodies by murine macrophages. Biochem. J. 239:121-125.

33. Saxena, U., M.G. Klein, T.M. Vanni, and I.J. Goldberg. 1992. Lipoprotein lipase increases low density lipoprotein (LDL) retention by subendothelial cell matrix. J. Clin. Invest. 89:373-380.

34. Obunike, J., I. Edwards, S. Rumsey, L. Curtiss, W. Wagner, R. Deckelbaum, and I. Goldberg. 1994. Cellular differences in lipoprotein lipase mediated uptake of low density lipoproteins. J. Biol. Chem. 269:13129-13135.

35. Williams, K.J., G.M. Fless, K.A. Petrie, M.L. Snyder, R.W. Brocia, and T.L. Swenson. 1992. Mechanisms by which lipoprotein lipase alters cellular metabolism of lipoprotein(a), low density lipoprotein, and nascent lipoproteins. Roles for low density lipoprotein receptors and heparan sulfate proteoglycans. J. Biol. Chem. 267:13284-13292.

36. Eisenberg, S., E. Sehayek, T. Olivecrona, and I. Vlodavsky. 1992. Lipoprotein lipase enhances the binding of lipoprotein to heparan sulfate on cell surfaces and extracellular matrix. J. Clin. Invest. 90:2013-2021.

37. Mulder, M., P. Lombardi, H. Jansen, B.T. Van, R.R. Frants, and L.M Havekes. 1992. Heparan sulphate proteoglycans are involved in the lipoprotein lipase-mediated enhancement of the cellular binding of very low density and low density lipoproteins. Biochem. Biophys. Res. Commun. 185:582-587.

38. Beisiegel, U., W. Weber, and G. Bengtsson-Olivecrona. 1991. Lipoprotein lipase enhances the binding of chylomicrons to low density lipoprotein receptor-related protein. Proc. Natl. Acad. Sci. USA. 88:8342-8346.

39. Obunike, J.C., S. Pillarisetti, S. Paka, A. Sasaki, and I.J. Goldberg. 1997. Lipoprotein lipase can function as a monocyte adhesion protein. Arterioscler. Thromb. Vasc. Biol. In press.

40. Traber, M., T. Olivecrona, and H. Kayden. 1985. Bovine milk lipoprotein lipase transfers tocopherol to human fibroblasts during triglyceride hydrolysis in vitro. J. Clin. Invest. 75:1729-1734.

41. Blaner, W.S., J.C. Obunike, S.B. Kurlandsky, M. al-Haideri, R. Piantedosi, R.J. Deckelbaum, and I.J. Goldberg. 1994. Lipoprotein lipase hydrolysis of retinyl ester. Possible implications for retinoid uptake by cells. J. Biol. Chem. 269:16559-16565.

42. Chait, A., P.H. Iverius, and J.D. Brunzell. 1982. Lipoprotein lipase secretion by human monocyte-derived macrophages. J. Clin. Invest. 69:490-493.

43. Yla-Herttuala, S., B. Lipton, M. Rosenfeld, I. Goldberg, D. Steinberg, and J. Witztum. 1991. Macrophages and smooth muscle cells express lipoprotein lipase in human and rabbit atherosclerotic lesions. Proc. Natl. Acad. Sci. USA. 88:10143-10147.

44. O'Brien, K., D. Gordon, S. Deeb, M. Ferguson, and A. Chait. 1992. Lipoprotein lipase is synthesized by macrophage-derived foam cells in human coronary atherosclerotic plaques. J. Clin. Invest. 89:1544-1550.

45. Arner, P. 1995. Impact of exercise on adipose tissue metabolism in humans. Int. J. Obes. Relat. Metab. Disord. 19 (Suppl. 4):18-21.

46. Coppack, S.W., M.D. Jensen, and J.M. Miles. 1994. In vivo regulation of lipolysis in humans. J. Lipid Res. 35:177-193.

47. Saltin, B., and P.O. Astrand. 1993. Free fatty acids and exercise. Am. J. Clin. Nutr. $57: 757 \mathrm{~s}-758 \mathrm{~s}$

48. Coyle, E.F. 1995. Substrate utilization during exercise in active people. Am. J. Clin. Nutr. 61:968s-979s.

49. Newsholme, P., and E.A. Newsholme. 1989. Rates of utilization of glucose, glutamine, and oleate and formation of end-products by mouse peritoneal macrophages in culture. Biochem. J. 261:211-218.

50. Goldberg, I.J., D.R. Soprano, M.L. Wyatt, T.M. Vanni, T.G. Kirchgessner, and M.C. Schotz. 1989. Localization of lipoprotein lipase mRNA in rat tissues. J. Lipid Res. 30:1569-1577.

51. Bessesen, D.H., C.L. Richards, J. Etienne, J.W. Goers, and R.H. Eckel 1993. Spinal cord of the rat contains more lipoprotein lipase than other brain regions. J. Lipid Res. 34:229-238.

52. Silverstein, S.C., R.M. Steinman, and Z.A. Cohn. 1977. Endocytosis. Annu. Rev. Biochem. 46:669-722.

53. Brunzell, J. 1989. Familial lipoprotein lipase deficiency and other causes of the chylomicronemia syndrome. In The Metabolic Basis of Inherited Disease. C.R. Scriber, A. Beaudet, W. Sly, and D. Valle, editors. McGraw Hill, Inc. New York. 1165-1180. 